\title{
INTEGRASI TEKNOLOGI DALAM PEMBELAJARAN MATEMATIKA: BELAJAR DARI SAMR DAN MAAAD
}

\author{
Muhammad Taqiyuddin'1), Faliqul Jannah Firdausi2), Mohamad Tri Afriyadi Nur \\ Asidin ${ }^{3)}$ \\ 1) University of Georgia, Athens, GA, USA; muhammad.taqiyuddin@uga.edu \\ 2) SMA Negeri 15 Bandung, Jl. Sarimanis I Kel. Sarijadi, Kota Bandung; faliqul.firdausi@gmail.com \\ 3)SMA Kuntum Cemerlang, Jl. Cipaku Indah XI No.2 Cidadap, Kota Bandung, triafriyadi@gmail.com
}

\begin{abstract}
Abstrak. Kita sedang menghadapi peningkatan kebutuhan penggunaan teknologi dalam pembelajaran matematika terutama karena era pandemi Covid-19 yang belum pernah terjadi sebelumnya. Dalam keadaan ini, sebagian besar guru di dunia termasuk Indonesia dipaksa untuk mempraktikkan pembelajaran jarak jauh tanpa menerima pelatihan dan pengalaman yang cukup. Artikel ini bertujuan untuk menjelaskan kepada para guru dan komunitas pendidikan matematika, khususnya di Indonesia, beberapa prinsip berbasis penelitian terutama dari kerangka kerja SAMR dan MAAAD terkait bagaimana mereka dapat menerapkan teknologi secara produktif dalam pembelajaran matematika. Dengan melakukan itu, kami menjelaskan bagaimana kita dapat meningkatkan integrasi teknologi dan bagaimana kita menganalisis ketergunaan teknologi. Selain itu, kami juga mengajukan pentingnya mengetahui keterbatasan teknologi yang dilanjutkan dengan diskusi tentang apa yang harus dilakukan seterusnya untuk meningkatkan keterampilan integrasi teknologi.
\end{abstract}

Kata Kunci. Integrasi Teknologi, MAAAD, Pendidikan Matematika, SAMR.

\section{Technology Integration in Mathematics Education: Learning from SAMR and MAAAD}

\begin{abstract}
We are now facing a growing demand of using technology in mathematics classrooms due to the unprecedented Covid-19 pandemics era. In this situation, most teachers among the globe including Indonesia have to employ remote learning practice without proper training and sufficient experience in doing so. This article aims to provide teachers and mathematics education communities, especially in Indonesia, with some research-based principles mainly from SAMR and MAAAD frameworks on how they productively incorporate technology in their mathematical teaching and learning. By doing so, we explain how we can improve our technology integration and how we analyse technology affordances. In addition, we also raise the importance of acknowledging technology limitations, along with the discussion on what to do next for improving our technology integration skills.
\end{abstract}

Keywords: MAAAD, Mathematics Education, SAMR, Technology Integration. 


\section{Pendahuluan}

Integrasi teknologi di kelas merupakan sebuah isu pendidikan yang esensial dan sejak lama menjadi tantangan bagi guru. Teknologi digital yang ada saat ini merupakan bagian tak terpisahkan dari perjalanan perkembangan teknologi yang sudah lama berlangsung dan akan terus berkembang di kemudian hari. Misalnya, salah satu pionir aplikasi geometri adalah Geometer's Sketchpad (The Geometer's Sketchpad, 2014; Finzer \& Bennett, 1995) yang penggunaannya terbatas. GeoGebra (https://www.geogebra.org) kemudian muncul sebagai salah satu alternatif gratis yang bisa diunduh dan digunakan secara offline maupun online. Ada banyak aplikasi lain yang bermunculan dan semakin canggih. Di saat yang sama, hal ini menimbulkan kesenjangan antara kecanggihan teknologi dan literasi teknologi guru agar bisa terus mengikuti dan memaksimalkan perkembangan teknologi. Gap dari teknologi dan penguasaannya oleh guru dapat dilihat dari berbagai macam masalah dan kesulitan muncul mulai dari teknis sampai ke tahap perancangan pembelajaran (Erduran \& Ince, 2018; Stein, Gurevich, \& Gorev, 2020). Hambatan yang dialami guru bisa karena kendala untuk mengakses internet atau karena keterbatasan pengalaman dan kemampuan dalam menggunakan teknologi secara efektif dan fleksibel (Adedoyin \& Soykan, 2020; Johns \& Mills, 2021; Mailizar et al., 2020).

Pandemik Covid-19 yang sedang melanda dunia mempertegas dan memperjelas kesenjangan antara penguasaan teknologi dan desakan penggunaannya. Sebagian dari kompleksitas masalah akibat musibah timbul akibat banyak guru yang tidak memiliki banyak pengalaman dalam penerapan teknologi juga karena kebutuhan pelatihan pelaksanaan pembelajaran jarak jauh yang belum tercapai (Hobbs \& Hawkins, 2020). Ketika sebagian besar guru belum siap, mereka terpaksa menjalankan pendidikan jarak jauh dengan pengetahuan dan pengalaman yang sangat minim. Dengan menyadari hal ini, kami mencoba menyusun kajian pustaka untuk berkontribusi dalam ranah penelitian pendidikan matematika dengan membahas dua kerangka yang berisi tentang panduan dalam integrasi teknologi. Kami juga membahas bagaimana memahami keduanya dalam konteks analisis dan penggunaan beberapa aplikasi populer.

Dua kerangka yang akan dibahas adalah Substitution, Augmentation, Modification, dan Redefinition (SAMR) (Puentedura, 2006) dan Modification of Attributes, Affordances, Abilities, and Distance (MAAAD) (Tucker, 2015; Johnson \& Tucker, 2018). Lebih lanjut, kami juga menyuguhkan ulasan beberapa aplikasi populer sebagai pendukung dalam uraian kerangka SAMR dan MAAAD yang menjadi pokok bahasan dalam tulisan ini. Pembahasan selanjutnya adalah terkait pentingnya memahami hambatan, kendala, dan kekurangan dari penggunaan sebuah teknologi yang juga diuraikan dengan dukungan bahasan aplikasi populer sebagai contoh. Tulisan ini akan diakhiri dengan uraian kompleksitas penerapan teknologi dalam kelas yang melewati batas-batas dari cakupan SAMR, MAAAD, dan analisis kekurangan teknologi yang kami bahas di sini. 


\section{SAMR}

Kerangka konseptual ini dikembangkan pada tahun 2006 oleh Ruben Puentedura (Puentedura, 2006). SAMR dapat membantu guru untuk berpikir tentang integrasi teknologi dan untuk memahami proses bertahap penggunaan teknologi dari sekadar Substitution sampai ke Redefinition. Dua kerangka pertama yakni Substitution dan Augmentation, dimaksudkan untuk meningkatkan pengajaran kita (enhancement), sementara yang lain dimaksudkan untuk mengubah cara kita mengajar dengan teknologi digital (transformation). Substitution adalah tahapan dimana teknologi digunakan hanya sebagai pengganti mode tradisional tanpa fungsi tambahan. Pada tahap augmentation, kita mendapatkan fungsi-fungsi tambahan dari penggunaan teknologi, misalnya terkait efisiensi. Selanjutnya, di tahap modification, teknologi digunakan untuk mendesain ulang pembelajaran secara signifikan. Yang terakhir adalah redefinition dimana teknologi digunakan untuk merombak kegiatan dan tugas yang dilakukan siswa yang sebelumnya tidak terbayangkan. Jika ingin merancang desain pembelajaran matematika dengan memanfaatkan suatu teknologi mengacu pada kerangka SAMR, guru dapat menggunakan diagram di Gambar 1 yang diadopsi dari Anderson (2013). Selanjutnya, akan dijelaskan contoh setiap tahap SAMR.

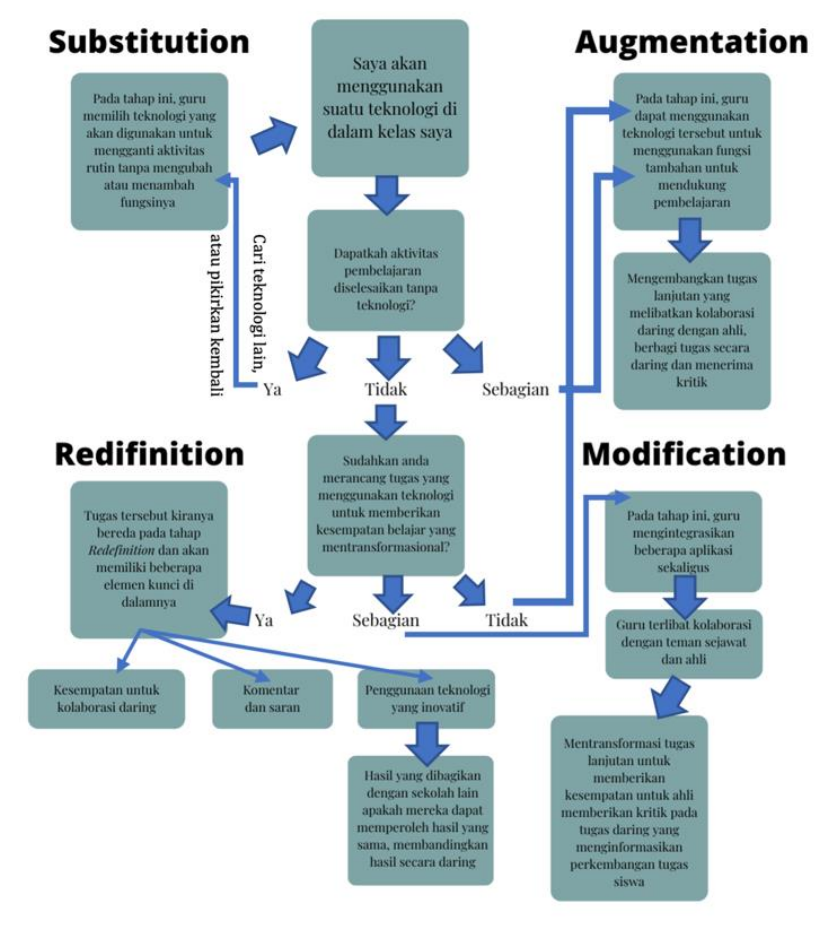

Gambar 1. Penerapan SAMR [diadaptasi dari Anderson (2013)]

\subsection{Substitution}

Contoh dari integrasi teknologi pada level terendah ini adalah ketika kita menggunakan Microsoft Word untuk mengetik alih-alih menggunakan pena dan kertas untuk menulis. Pada level ini, apa yang kita lakukan dengan teknologi sama dengan tanpa teknologi. 
Contoh lainnya adalah ketika kita menerapkan ulangan harian menggunakan Google Form (https://docs.google.com/forms) dengan tanpa otomatisasi penilaian. Penggunaan Zoom (https://zoom.us) untuk mengganti jam tatap muka dengan siswa juga merupakan substitution.

\subsection{Augmentation}

Pada level ini, kita menggunakan teknologi agar lebih efisien daripada yang biasanya kita lakukan dengan cara tradisional. Contohnya adalah Google Form yang digunakan untuk melakukan tes dengan soal pilihan ganda dan menggunakan otomatisasi penilaian. Kita tidak perlu melakukan penilaian manual yang biasanya dilakukan saat menilai kertas lembar jawaban siswa dan memakan waktu berjam-jam. Dalam contoh ini, terdapat peningkatan fungsional yang kita rasakan dengan menggunakan teknologi di kelas, sehingga penerapan teknologi seperti ini dapat dikategorikan sebagai augmentation.

\subsection{Modification}

Salah satu contoh dari level ini adalah penggunaan e-Learning. Kita dapat memberikan tugas yang mencakup video, bacaan, atau audio (seperti podcast atau radio). Respon atau jawaban siswa yang kita inginkan bisa jadi sama dengan apa yang kita tugaskan kepada siswa dalam cara tradisional seperti dalam bentuk esai satu halaman atau menjawab suatu paket soal, tetapi cara tugas dirancang berbeda dengan melibatkan tiga media tersebut. Contoh serupa adalah ketika kita menggunakan Schoology (https://www.schoology.com). Kita dapat merekam semua nilai siswa dan memanfaatkan teknologi untuk memproses nilai akhir. Kita juga dapat memberikan feedback kepada siswa untuk setiap tugas yang siswa masukkan, mengatur kalender akademik, menyediakan pengingat untuk batas waktu pengumpulan tugas dan memposting tugas di sana. Dalam tahap ini, terdapat manfaat fungsional yang sangat signifikan dan tugas yang diberikan dapat bervariatif.

\subsection{Redefinition}

Contoh pada level ini adalah ketika kita menugaskan siswa untuk membuat sebuah episode atau serangkaian podcast dimana mereka dapat merekam dirinya sendiri atau mewawancarai orang lain secara interaktif untuk membahas, misalnya, bagaimana caranya untuk menggunakan ide-ide matematika dalam kehidupan nyata. Contoh lainnya adalah dengan meminta siswa untuk membuat video untuk menjelaskan biografi ahli matematika atau mereka dapat mewawancarai ahli matematika dan berbicara tentang keahlian mereka, misalnya menggunakan rekaman Zoom. Selain itu, memposting karya seni pola geometris di Instagram dan kemudian menjelaskan matematika di balik karya tersebut di Instagram Live yang kemudian kita simpan rekamannya bisa menjadi ide kreatif untuk mendefinisikan ulang tugas matematika. 


\subsection{Penerapan SAMR}

Kerangka kerja ini memberitahu kita bagaimana kita secara bertahap dapat meningkatkan keterampilan teknologi kita (lihat Gambar 1). Misalnya, kita sadar bahwa penggunaan teknologi kita sebatas untuk mempermudah kita dalam melaksanakan tugas-tugas administrasi semacam menilai ulangan dengan menggunakan Google Form. Selanjutnya, mungkin kita bisa meningkatkan penggunaan teknologi dengan memaksimalkan ekosistem Google dengan menggunakan Google Website (https://sites.google.com/) untuk kelas memposting semua tugas, deadline, dan rekap nilai siswa dalam satu wadah. Menurut kami, level penerapan kita dalam penggunaan teknologi berdasarkan SAMR tidak bergantung kepada teknologinya melainkan bagaimana kita memanfaatkan teknologi itu. Selanjutnya kami akan membahas hal ini secara detail dengan menggunakan contoh dari penggunaan dua teknologi yakni Actively Learn (https://www.activelylearn.com) dan Flipgrid (https://flipgrid.com). Walaupun menggunakan teknologi yang sama, level penerapan kita bisa berbeda sebagaimana akan dijelaskan nanti.

\subsubsection{Actively Learn}

Teknologi ini adalah platform membaca yang dibentuk pada tahun 2012 oleh Deep Sran dan Jay Goyal (Actively Learn, 2019). Kita dapat menggunakan situs web ini untuk mengontrol bagaimana siswa membaca dokumen. Kita dapat menambahkan beberapa pertanyaan untuk satu paragraf, satu kalimat, satu kata, ataupun bagian dari tulisan lain. Selanjutnya, kita juga dapat mengatur agar siswa harus menjawab pertanyaan tadi atau memberikan komentar pada bagian teks tertentu sebelum mereka dapat beralih ke teks berikutnya. Setelah selesai menjawab, siswa juga dapat melihat jawaban siswa lain dan memberikan komentar atau like. Kami akan memberikan dua contoh penerapan dalam tahap augmentation dan modification.

\subsubsection{Augmentation}

Jika aplikasi ini digunakan untuk memberikan tugas bacaan kepada siswa dan mengumpulkan jawaban siswa tanpa adanya diskusi kelompok atau kelas, maka kami mengkategorikannya ke dalam augmentation. Alasannya adalah karena tugas yang diberikan sama saja dengan cara tradisional dan mendapat manfaat dari otomatisasi pengumpulan jawaban dan penilaian.

\subsubsection{Modification}

Aplikasi ini dapat digunakan untuk membuat siswa memberi anotasi pada beberapa kutipan, dan memulai diskusi kelas. Kita juga dapat menugaskan siswa untuk menanggapi komentar orang lain pada bagian tertentu dari bacaan. Jika demikian halnya, integrasi seperti ini adalah modification karena sifat tugasnya berbeda meskipun respon siswa yang kita inginkan tidak berubah drastis dari pembelajaran tradisional. 


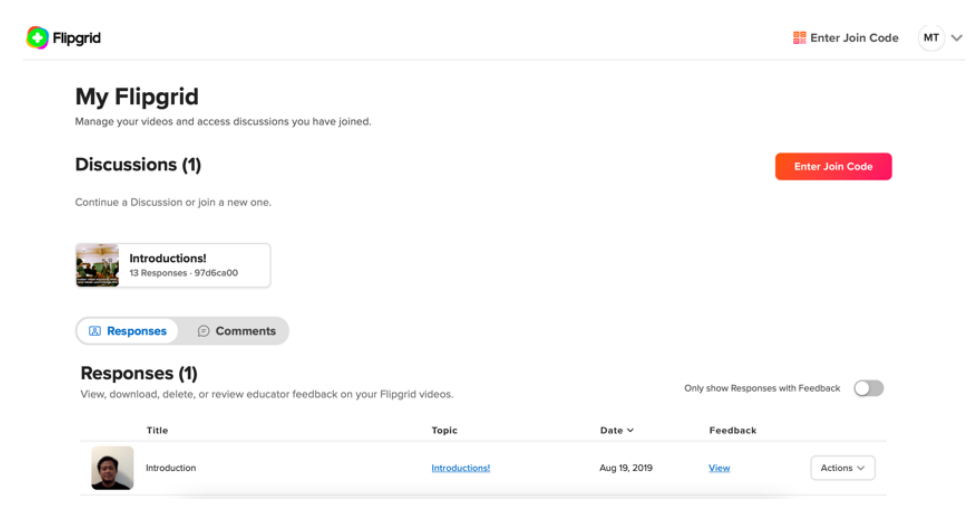

Gambar 2. Tampilan Flipgrid

\subsubsection{Flipgrid}

Aplikasi ini adalah sebuah platform untuk berdiskusi melalui unggahan video. Selain tersedia dalam versi Android dan iOS, kita juga dapat mengakses aplikasi ini dari web browser (lihat Gambar 2). Guru dapat memposting instruksi diskusi dalam sebuah teks pertanyaan atau video sedangkan siswa dapat langsung merekam atau mengunggah video dari ponsel, tablet, maupun komputer atau laptop. Saat ini, video yang dapat diunggah di Flipgrid memiliki batasan waktu, misalnya tiga menit untuk video tanggapan, yang mana kita perlu sadari dan antisipasi. Guru memiliki pilihan untuk tidak membiarkan siswa melihat unggahan asli orang lain sebelum disetujui atau setelah mengunggah video mereka.

\subsubsection{Substitution}

Jika kita tidak menggunakan fitur tahan atau tunda agar siswa tidak melihat video asli siswa lain, kami berpendapat bahwa integrasi ini adalah substitusi karena mirip dengan skenario yang terjadi di kelas dimana siswa dapat berkomentar dan mendengar apa yang didiskusikan seluruh siswa di kelas.

\subsubsection{Augmentation}

Kami berpendapat bahwa aplikasi ini dapat dikategorikan ke dalam augmentation karena guru dapat menggunakannya untuk mengatur bagaimana siswa memposting dan merespon jawaban temannya dan siswa juga berkesempatan untuk menonton secara berulang video yang diposting di Flipgrid. Dengan kata lain, ada fungsi tambahan dari aplikasi ini dibandingkan dengan diskusi verbal di kelas.

\section{MAAAD}

MAAAD menjelaskan atribut aplikasi, atribut pengguna, serta hubungan antara aplikasi dan pengguna (Tucker, 2015; 2016; 2018). Ketiga hal tersebut (lihat Gambar 3) sangat berpengaruh dalam kesuksesan kita dalam mengaplikasikan teknologi di kelas. Tucker (2015, 2016, 2018) mengungkapkan bahwa terdapat kesenjangan antara kemampuan siswa, sebagai pengguna, dengan fitur-fitur aplikasi matematika yang terbagi menjadi 
dua yakni gap matematis (mathematical distance) dan gap teknologi (technological distance). Yang pertama mengindikasikan adanya gap antara pengetahuan dan kemampuan matematika siswa dengan ide-ide matematika yang terkandung dalam fitur-fitur matematika dalam aplikasi. Di sisi lain, gap teknologi menjelaskan adanya kesenjangan antara kemampuan siswa dalam menggunakan aplikasi dan fungsi-fungsi yang ada dalam aplikasi. Tucker $(2015,2016,2018)$ menambahkan bahwa guru sebaiknya mampu mengevaluasi kedua gap ini dan mencoba memperkecilnya agar pembelajaran dapat berjalan secara maksimal. Misalnya, guru perlu memastikan siswa menguasai materi prasyarat yang perlu untuk memahami konten matematika yang tercakup dalam teknologi. Selanjutnya, kami akan membahas atribut aplikasi dan pengguna secara lebih rinci dan dilanjutkan dengan contoh bagaimana cara menganalisis atribut teknologi.

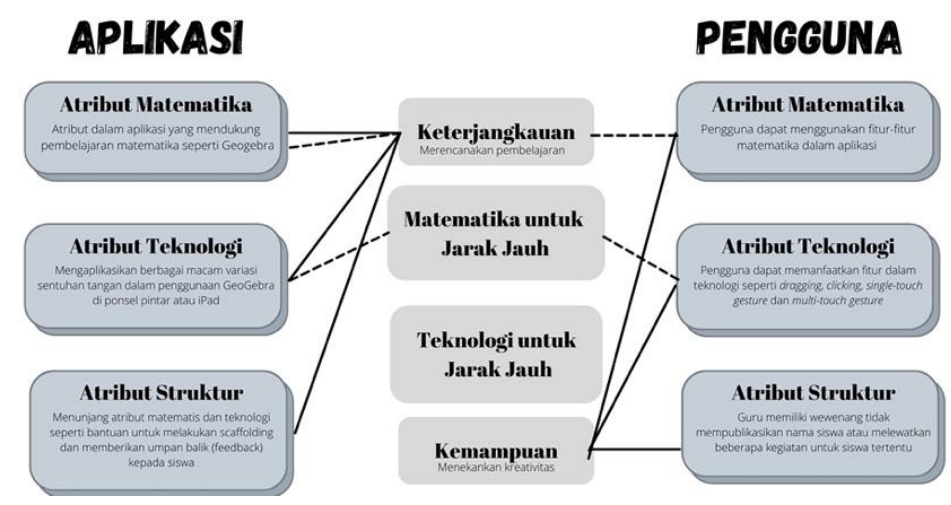

Gambar 3. Kerangka MAAD [diadaptasi dari Tucker (2018)

\subsection{Atribut Aplikasi}

Atribut aplikasi terbagi menjadi tiga yakni: matematis, teknologi, dan struktural. Pertama, atribut matematis dari aplikasi merupakan konsep dan representasi matematis yang tersedia dalam aplikasi. Misalnya, konstruksi geometris dalam GeoGebra di antaranya adalah menggambar lingkaran dan rotasi. Kedua, atribut teknologi merujuk kepada interaksi fisik dengan aplikasi. Contohnya, kita dapat mengaplikasikan berbagai macam variasi sentuhan tangan dalam penggunaan GeoGebra di ponsel pintar atau iPad. Ketiga, atribut struktural mengacu kepada elemen-elemen dalam aplikasi yang menunjang atribut matematis dan teknologi seperti bantuan untuk melakukan scaffolding dan memberikan umpan balik (feedback) kepada siswa. Sebagai contoh, GeoGebra memiliki mode tes yang membatasi siswa untuk menggunakan beberapa fiturnya.

\subsection{Atribut Pengguna}

Atribut pengguna terbagi juga menjadi tiga: matematis, teknologi, dan personal. Pertama, atribut matematis terkait dengan pengetahuan prasyarat (prior knowledge) yang meliputi konten dan representasi matematis. Misalnya, siswa perlu mengetahui kosakata transformasi geometris untuk menggunakan aplikasi GeoGebra. Kedua, atribut teknologi mencakup keterampilan motorik siswa dan kebiasaan siswa dalam 
penggunaan aplikasi. Berdasarkan hal ini, penting untuk memperkenalkan sebuah aplikasi sebelum memberikan sebuah tugas kepada siswa. Ketiga, atribut personal merujuk kepada karakteristik pribadi pengguna yang berpengaruh terhadap interaksinya dengan aplikasi seperti bagaimana sikap, tujuan, dan motivasi.

\subsection{Analisis Atribut Aplikasi}

Selanjutnya akan dibahas dua buah teknologi digital berbasis web yakni Teacher Desmos (https://teacher.desmos.com) dan ClassPad.net (https://classpad.net/us) berdasarkan atribut aplikasi yang terkandung di dalam keduanya.

\subsubsection{Teacher Desmos}

Teknologi berbasis web ini menyediakan bahan pengajaran yang dapat kita gunakan untuk mengajarkan topik matematika baik untuk penggunaan di kelas maupun pembelajaran jarak jauh. Sebagian besar aktivitas berisi beberapa layar dimana siswa melakukan kegiatan-kegiatan seperti berikut: memperhatikan representasi matematis, menjawab pertanyaan, membandingkan jawaban mereka dengan siswa lain, dan bermain dengan beberapa grafik dinamis atau objek geometris. Desmos juga menyediakan panduan untuk guru agar penerapan di kelas lebih maksimal.

Atribut Matematis: Dalam hal fitur matematika, Teacher Desmos menyediakan fiturfitur yang ada di aplikasi Desmos yang di antaranya adalah kalkulator grafis dan konstruksi geometris. Hal lain yang bisa kita lakukan adalah mengubah data ke dalam kurva normal, dan mencari regresi linier, regresi logaritmik dan analisis statistik lainnya.

Atribut Teknologi: Gerakan motorik yang dapat dilakukan pada aplikasi ini terbatas pada dragging, clicking, single-touch gesture dan multi-touch gesture (Tucker, 2018) yang bergantung pada perangkat yang digunakan.

Atribut Struktural: Guru memiliki wewenang untuk tidak mempublikasikan nama siswa, menghentikan sementara pekerjaan siswa, atau melewatkan beberapa kegiatan untuk siswa tertentu. Selain itu, kita juga dapat menampilkan video ataupun menambahkan pertanyaan di Teacher Desmos.

\subsubsection{ClassPad.net}

Penggunaan Classpad dapat diibaratkan seperti merancang aktivitas pembelajaran di atas kertas kosong. Kita dapat memilih berbagai macam "sticky notes" yang berupa grafik, catatan tempel, geometri, statistik, urutan, dan kalkulator. Salah satu keunggulan dari teknologi ini adalah untuk membandingkan representasi matematika yang berbeda sekaligus dalam satu "halaman" atau "kertas". Selain merancang aktivitas untuk siswa, kita juga bisa menggunakan desain pembelajaran yang sudah dibuat orang lain yang tersedia di ClassPad.net. 
Atribut Matematis: Kita dapat mengaplikasikan konstruksi dan transformasi geometris, menampilkan grafik dari sebuah fungsi dan menganalisis data statistik. Selain itu, kita dapat menampilkan tabel dan grafik dari sebuah barisan yang kita tentukan rumusnya dalam "sticky notes".

Atribut Teknologi: Sama halnya dengan Teacher Desmos, atribut teknologi dari aplikasi ClassPad.net terbatas pada berbagai gestur tangan pada layar sentuh (touchscreen), keyboard dan mouse.

Atribut Struktural: Kita dapat melihat, memilah, dan memilih beberapa aktivitas yang sudah dibuat dan siap digunakan di kelas. Kita juga dapat menyunting aktivitas yang sudah ada agar sesuai dengan desain pembelajaran yang kita inginkan. Selain itu siswa dapat menyimpan tugas yang mereka kerjakan ketika belum selesai, kemudian kembali lagi ke tahap selanjutnya di lain waktu, dan selanjutnya mengirimkannya (submit) setelah selesai.

\section{Kekurangan dari Teknologi}

Dengan mempelajari SAMR dan MAAAD, kita memahami ketergunaan teknologi (affordances) dan bagaimana kita memanfaatkannya. Namun, kami juga sadar akan perlunya menganalisis kekurangan, masalah, dan hambatan yang timbul dari penggunaannya. Hal ini krusial agar kita juga sadar akan ketidaksempurnaan suatu teknologi dan mempersiapkan solusi-solusi alternatif. Sebagai contoh, kami akan menggambarkan permasalahan yang kami temukan selama pelaksanaan pembelajaran daring di suatu sekolah di Jawa Barat. Dinas Pendidikan Jawa Barat (Disdik Jabar) (2020) sedang menyiapkan aplikasi Cerdazz sebagai media pembelajaran di rumah. Namun, selama aplikasi Cerdazz disiapkan, Disdik Jabar merekomendasikan beberapa teknologi digital yang digunakan untuk mendukung pembelajaran jarak jauh selama pandemi Covid-19 yang diantaranya adalah WhatsApp, selanjutnya disebut WA, dan Google Classroom (https://classroom.google.com/). Dalam subbab ini, kami mengkaji dari WA dan Google Classroom berdasarkan pengalaman guru dan siswa.

\subsection{WhatsApp}

WA merupakan aplikasi pesan yang populer dan lazim digunakan untuk menyampaikan informasi terkait sekolah, misalnya dalam grup kelas yang ada di WA. WA juga dapat dijadikan sebagai media penyampaian materi selama pembelajaran daring. Masalah dalam penggunaan WA terkait dengan kerancuan pesan yang ada dalam grup WA. Terkadang, topik yang dibicarakan selama proses pembelajaran tidak teratur dengan baik dan keluar dari topik sehingga membuat pembaca pesan, baik guru maupun siswa, merasa bingung. Lebih lanjut, sampai saat ini, belum ada fitur untuk mengatur topik pembicaraan di WA seperti tagar yang ada di Instagram ataupun Channel di Microsoft Teams (https://teams.microsoft.com/). Selain itu, tidak ada fitur untuk membisukan siswa sehingga guru tidak dapat mengatur siapa yang boleh menyampaikan pesan dan siapa yang tidak. 


\subsection{Google Classroom}

Kelas virtual ini memiliki beberapa fitur yang memudahkan dalam pengaturan daftar nilai dari tugas, penyerahan tugas oleh siswa, dan umpan balik (feedback) dari guru. Meskipun Google Classroom (GC) memudahkan guru dan siswa dalam mengelola tugas harian, ulangan harian, ataupun nilai, GC memiliki kekurangan terkait privasi antar guru. Ketika seorang guru memberikan tugas ke siswa, yang dapat memberikan komentar pribadi ke siswa tidak hanya guru yang memberikan tugas, namun juga guru lainnya. Hal ini mengganggu ruang privasi pengampu pelajaran dalam memberikan masukan, koreksi, ataupun ulasan mengenai tugas siswa yang seharusnya menjadi konsumsi pribadi guru dan siswa yang bersangkutan. Selain itu, salah satu fitur yang sering digunakan di GC adalah Google Meet, yaitu layanan conference call untuk pembelajaran tatap muka secara tidak langsung dengan fitur standar seperti broadcast screen, record meet, dan beberapa fitur penunjang yang harus dipasang melalui G Suite Marketplace. Jika dibandingkan dengan kompetitor lain, Google Meet memiliki beberapa kekurangan, di antaranya, tidak adanya fitur mematikan chat room juga guru tidak memiliki kuasa penuh untuk melakukan mute dan unmute siswa yang menjadi peserta meeting.

\section{WHAT TO DO NEXT? MOVING AHEAD!}

Kami mencoba mengusung beberapa pedoman yang dapat membantu guru dalam mendesain pembelajaran matematika dengan memanfaatkan teknologi secara bermakna. Beberapa pedoman berikut juga mengisyaratkan bahwa peningkatan kemampuan teknologi bukanlah suatu proses linear namun sebuah evolusi kompleks yang melibatkan berbagai macam aspek.

\subsection{Fokus kepada pembelajaran matematika}

Teknologi seharusnya menjadi penyokong bagi pembelajaran matematika bukan menjadi penghambat yang mempersulit pembelajaran; Kita perlu lebih berfokus terhadap desain pembelajaran yang kaya dengan aktivitas matematis menjadi penggerak pembelajaran sedangkan teknologi sebagai mesin pendorong yang mempercepat, mempermudah, dan memberikan pengalaman yang tanpanya pembelajaran menjadi kurang bermakna (Belnap \& Parrott, 2020). Prinsip ini mengingatkan kita bahwa yang terpenting adalah pembelajaran matematika yang dinikmati oleh siswa bukan seberapa canggih teknologi yang kita terapkan. Hal ini akan membantu kita untuk terhindar dari hype dari suatu teknologi yang sangat menggiurkan untuk dicoba di kelas tanpa tahu dan menganalisa kebermanfaatan dan kekurangannya terkait dengan pembelajaran yang bermakna bagi siswa.

\subsection{Kemauan untuk mengeksplorasi teknologi terbaru}

Dengan menyadari bahwa teknologi akan terus berkembang, guru diharapkan memiliki semangat untuk terus mau mengeksplorasi teknologi terkini sebagai bentuk kesadaran dan tanggung jawab atas peran pentingnya dalam menyajikan pembelajaran 
yang aktual (Campe, 2011). Eksplorasi teknologi di sini bermakna bukan hanya bermakna bahwa kita dituntut untuk tahu teknologi-teknologi terbaru namun juga bagaimana penggunaannya dalam pembelajaran yang bermakna dan keterbatsannya yang perlu diantisipasi. Teknis yang kita lakukan dalam eksplorasi ini bisa bervariasi misalnya dengan mengikuti kegiatan seminar dan konferensi ilmiah, ataupun membaca jurnal teknologi pendidikan, majalah pendidikan, artikel ilmiah dalam jurnal maupun artikel populer di koran maupun media yang lain yang membahas integrasi teknologi. Selain itu, kelompok diskusi guru juga merupakan ruang yang bagus untuk berbagi informasi penggunaan teknologi. Semua itu dilakukan dalam rangka untuk memperkaya pengetahuan guru, memberikan pelbagai alternatif pilihan teknologi, serta kemampuan untuk memilah dan memilih teknologi yang tepat untuk diterapkan dalam pembelajaran tertentu.

\section{SIMPULAN DAN SARAN}

Dalam artikel ini, kami mengajukan beberapa ide dalam memahami penerapan teknologi di kelas yakni, yang pertama, agar guru memahami bagaimana level penerapan dengan pedoman kerangka SAMR. Yang kedua adalah bahwa guru perlu menganalisis teknologi yang digunakan di kelas dari segi matematis, teknologi, dan didaktis dengan bantuan kerangka MAAAD. Dengan menggunakan kedua pedoman tersebut, kami meyakini bahwa kemampuan guru dalam integrasi teknologi dalam pembelajaran matematika akan terus berkembang. Selain itu, kami juga menyatakan bahwa penting bagi guru untuk memperhatikan kekurangan dari sebuah teknologi agar dapat memiliki ekspektasi yang realistis dan mampu memikirkan solusi yang tepat sasaran.

Meskipun demikian, apa yang kami utarakan di artikel ini merupakan hal-hal yang mendasar dari peningkatan kemampuan integrasi teknologi yang dapat dilakukan oleh guru. Lebih spesifiknya, kami berpendapat bahwa dimensi permasalahan penggunaan teknologi lebih kompleks dan dinamis dari apa yang kami bahas di artikel ini. Ada begitu banyak faktor lain yang penting misalnya adalah tentang bagaimana peran komunitas guru dalam membahas integrasi teknologi baik dalam lingkup sekolah, MGMP, nasional, bahkan internasional (Niess, et al., 2009). Peran komunitas pengajar ini memiliki dampak yang luar biasa dalam membangun sebuah kultur pembelajaran yang terus bertransformasi dan berkembang menyesuaikan perkembangan zaman dan teknologi.

\section{UCAPAN TERIMA KASIH}

Penulis pertama berterimakasih kepada Kelly Edenfield atas ide dan materi untuk tulisan ini. 


\section{Daftar Pustaka}

Actively Learn. (2019). About us. https://www.activelylearn.com/about-us

Adedoyin, O. B., \& Soykan, E. (2020). Covid-19 pandemic and online learning: The challenges and opportunities. Interactive Learning Environments, 1-13. https://doi.org/10.1080/10494820.2020.1813180

Anderson, M. (2013). SAMR Flow chart. [Online]. Tersedia di: https://ictevangelist.com/wpcontent/uploads/2013/03/SAMR-flow-chart.pdf. Diakses tanggal: 5 Mei 2021.

Belnap, J. K., \& Parrott, A. (2020). Putting Technology in Its Place. Mathematics Teacher: Learning and Teaching PK-12, 113(2), 140-146.

Dinas Pendidikan Provinsi Jawa Barat. (2020). Pedoman belajar dari rumah (BDR) jenjang SMA, SMK, SLB, dan adaptasi kebiasaan baru (AKB) sekolah di provinsi Jawa Barat tahun ajaran 2020/2021 [Surat Pemberitahuan]. Bandung: Dinas Pendidikan Provinsi Jawa Barat.

Campe, K. D. (2011). Do It Right-Strategies for Implementing Technology. The Mathematics Teacher, 104(8), 620-625.

Erduran, A., \& Ince, B. (2018). Identifying Mathematics Teachers' Difficulties in Technology Integration in Terms of Technological Pedagogical Content Knowledge (TPCK). International Journal of Research in Education and Science, 4(2), 555-576.

Finzer, W. F., \& Bennett, D. S. (1995). From drawing to construction with the Geometer's Sketchpad. The Mathematics Teacher, 88(5), 428.

Hobbs, T.D., \& Hawkins, L. (2020, June 5). The results are in for remote learning: it didn't work. https://www.wsj.com/articles/schools-coronavirus-remote-learning-lockdown-tech11591375078?st=q4p9gu24xnc97sy\&reflink=article_copyURL_share

Johns, C., \& Mills, M. (2021). Online Mathematics Tutoring During the COVID-19 Pandemic: Recommendations for Best Practices. PRIMUS, 31(1), 99-117. https://doi.org/10.1080/10511970.2020.1818336

Johnson, T. N., \& Tucker, S. I. (2018). Get MAAAD at Those Apps!. Mathematics Teaching in the Middle School, 23(6), 343-348.

Niess, M. L., Ronau, R. N., Shafer, K. G., Driskell, S. O., Harper S. R., Johnston, C., Browning, C., Özgün-Koca, S. A., \& Kersaint, G. (2009). Mathematics teacher TPACK standards and development model. Contemporary Issues in Technology and Teacher Education, 9(1), 4-24.

Puentedura, R. (2006). Transformation, technology, and education [Blog post]. Retrieved from http://hippasus.com/resources/tte/.

Romrell, D., Kidder, L., \& Wood, E. (2014). The SAMR model as a framework for evaluating mLearning. Online Learning Journal, 18(2).

Stein, H., Gurevich, I., \& Gorev, D. (2020). Integration of technology by novice mathematics teachers-what facilitates such integration and what makes it difficult?. Education and Information Technologies, 25(1), 141-161.

Tucker, S. I. (2015). An exploratory study of attributes, affordances, abilities, and distance in children's use of mathematics virtual manipulative iPad apps (Doctoral dissertation, Utah State University).

Tucker, S. I. (2016). The modification of attributes, affordances, abilities, and distance for learning framework and its applications to interactions with mathematics virtual manipulatives. In International perspectives on teaching and learning mathematics with virtual manipulatives (pp. 41-69). Springer, Cham.

Tucker, S. I. (2018). Applying the Modification of Attributes, Affordances, Abilities, and Distance for Learning Framework to a Child's Multi-touch Interactions with an Idealized Number Line. In Uses of technology in primary and secondary mathematics education (pp. 35-57). Springer, Cham. 